Original Research Paper

\title{
Analisis Kemampuan Literasi Sains Siswa SMP pada Materi Sirkulasi Darah
}

\author{
Siti Hardiyanti Hasasiyah ${ }^{1 *}$, Bagus Addin Hutomo ${ }^{1}$, Bambang Subali ${ }^{1}$, Putut Marwoto ${ }^{1}$ \\ ${ }^{1}$ Program Pascasarjana Universitas Negeri Semarang, Indonesia.
}

DOI: $10.29303 /$ ippipa.v6i1.193

Sitasi: Hasasiyah, S. H., Hutomo, B. A., Subali, B., \& Marwoto, P. 2020. Analisis Kemampuan Literasi Sains Siswa SMP pada Materi Sirkulasi Darah. Jurnal Penelitian Pendidikan IPA (JPPIPA). 6(1). pp. 5-9

\section{Article history}

Received: December $6^{\text {th }} 2018$

Revised: September $18^{\text {th }} 2019$

Accepted: October $14^{\text {th }} 2019$

*Corresponding Author: Siti Hardiyanti Hasasiyah: Program Pascasarjana Universitas Negeri Semarang, Indonesia.

Email: hasasiyah@gmail.com

\begin{abstract}
Science literacy is the ability to use science knowledge to identify questions, explain scientific phenomena that occur using contextual facts. The circulation theme is one of the themes of contextual learning that is very closely related to everyday life. This study aims to determine the scientific literacy skills of students in blood circulation material at the junior high school level. The research method used was descriptive qualitative with scientific literacy instruments in the form of tests with research subjects 38 students of SMP N 4 Belik class VIIID academic year 2018/2019. The results of this study indicate that students' literacy skills in the category are low. This can be seen from the aspect of identifying valid scientific opinions (58\%), understanding the design elements of the research findings (24\%), being able to solve questions based on scientific phenomena (32\%), understanding and interpreting basic statistics (21\%) and students able to make inferences, predictions, and draw conclusions based on data (39\%). The value obtained by students is divided into four categories of values obtained by students, which are very low, low, sufficient, and high based on the results of research, the average literacy skills of students in the low category. The conclusion of this study is that the science literacy skills of junior high school students are low on aspects of understanding and interpreting basic statistics.
\end{abstract}

Keywords: Science Literacy, Contextual, Blood Circulation

Abstrak: Literasi sains merupakan kemampuan menggunakan pengetahuan sains untuk mengidentifikasi pertanyaan, menjelaskan fenomena sains yang terjadi dengan menggunakan fakta-fakta kontekstual. Tema sirkulasi salah satu tema pembelajaran kontekstual yang sangat erat dengan kehidupan sehari-hari. Penelitian ini bertujuan untuk mengetahui kemampuan literasi sains siswa pada materi sirkulasi darah di tingkat SMP. Metode penelitian yang digunakan adalah deskriptif kualitatif dengan instrumen literasi sains berupa tes dengan subjek penelitian 38 siswa SMP N 4 Belik Pemalang Jawa Tengah kelas VIIID tahun ajaran 2018/2019. Hasil penelitian ini menunjukkan bahwa kemampuan literasi sains siswa pada kategori rendah. Hal ini tampak dari aspek mengidentifikasi pendapat ilmiah yang valid (58\%), memahami elemen-elemen desain penelitian terhadap temuan (24\%), mampu menyelesaikan soal berdasarkan fenomena ilmiah (32\%), memahami dan menginterpretasikan statistik dasar (21\%) dan siswa mampu melakukan inferensi, prediksi, dan penarikan kesimpulan berdasarkan data (39\%). Adapun berdasarkan nilai yang diperoleh siswa dibagi menjadi empat kategori nilai yang diperoleh siswa yaitu sangat rendah, rendah, cukup, dan tinggi berdasarkan hasil penelitian rata-rata kemampuan literasi sains siswa masuk dalam kategori rendah. Kesimpulan dari penelitian ini adalah kemampuan literasi sains siswa SMP rendah pada aspek memahami dan menginterpretasikan statistik dasar.

Kata Kunci: Literasi sains, Kontekstual, Sirkulasi Darah 


\section{Pendahuluan}

Tantangan era distrubsi merupakan tantangan yang harus kita hadapi dengan mempersiapkan generasi-generasi siswa yang dapat membangun dan menerapkan informasi pengetahuan yang logis, kritis, kreatif, dan inovatif serta mampu menganalisis dan memanfaatkan fenomena alam serta lingkungan sekitar sebagai sumber belajar yang bermakna dan dapat mengaplikasikannya dalam kehidupan sehari hari secara kontekstual. Adapun penyusunan perangkat pembelajaran sebagai acuan implementasi keterampilan abad 21 dalam penerapan kurikulum 13 harus memfasilitasi empat hal, yaitu: Penguatan Pendidikan Karakter (PPK), 4C, HOTS, dan literasiyang bersifat kontekstual (Harjono, 2019).

Salah satu pembelajaran kontekstual harus mengedepankan melek sains atau literasi sains. Literasi sains merupakan kemampuan untuk mengidentifikasi pertanyaan, memperoleh pengetahuan baru, menjelaskan fenomena ilmiah dan menarik kesimpulan berdasarkan fakta dan bukti ilmiah terkait konsepkonsep sains (OECD, 2009: 128).

Literasi berasal dari "literacy" yang berarti melek huruf, sementara sains berasal dari "science" yang berarti ilmu pengetahuan (Echols dan Shadily, 1990). Literasi sains yaitu suatu ilmu pengetahuan dan pemahaman mengenai konsep dan proses sains yang memungkinkan seseorang untuk membuat suatu keputusan dengan pengetahuan yang dimilikinya sehingga literasi sains akan mampu berperan aktif dalam segala segi kehidupan terutama pada bidang ilmu yang digelutinya (Holbrook, dan Rannikmae, 2009).

Kemampuan literasi sains yaitu kemampuan menggunakan data dan bukti ilmiah untuk mengevaluasi kualitas informasi dan argumentasi ilmiah (Literasi sains berkaitan dengan pengetahuan, pemahaman, keterampilan dan nilai-nilai yang terdapat di dalam sains (Huryah, 2017) Pembelajaran sains, siswa diharapkan memiliki keterampilan dan mampu mengaplikasikannya ke dalam kehidupan sehari-hari (Taofiq, 2018).

Programme for International Student Assessment (PISA) merupakan studi yang bertujuan untuk mengetahui hasil sistem pendidikan yang berkaitan dengan kemampuan literasi siswa usia 15 tahun. Studi PISA dilakukan di beberapa negara maju dan berkembang mulai tahun 2000 dengan interval tiga tahun sekali. Bidang kajian yang diteliti dan dinilai meliputi literasi membaca (reading literacy), literasi matematika (mathematical literacy), dan literasi sains (scientific literacy). Hasil studi PISA sejak tahun 2000 hingga tahun 2012 menunjukkan peringkat Indonesia terus menurun.
Tahun 2012 literasi sains siswa Indonesia berada pada tingkat 64 dari 65 negara peserta dengan skor 382. Skor ini masih jauh di bawah skor rata-rata Internasional yang ditetapkan PISA yaitu 500 (OECD, 2013:5). Skor rata-rata Indonesia yang masih tergolong rendah ini mencerminkan bahwa siswa di Indonesia 59 sebagian besar belum mampu menganalisis dan mengaplikasikan konsep untuk menyelesaikan suatu masalah. Para siswa sangat pandai menghafal, namun masih kurang terampil dalam menggunakan pengetahuan yang dimilikinya. Adapun fenomena yang terjadi sekarang adalah tingkat kemauan siswa untuk membaca dan menulis sangat kurang, sehingga kemampuan literasi siswa yang lain termasuk literasi sains ikut berkurang (Faisal, 2018).

Hasil capaian tersebut juga mengindikasikan bahwa rata-rata kemampuan sains siswa Indonesia baru sampai pada kemampuan mengingat dan mengenali pengetahuan ilmiah berdasarkan fakta sederhana tetapi belum mampu untuk mengkomunikasikan dan mengaitkan berbagai topik sains, apalagi menerapkan konsep-konsep yang kompleks dan abstrak di dalam kehidupan sehari-hari. Sedangkan ilmu Pendidikan harus membekali siswa untuk berpartisipasi pada lingkungan dalam membangun dan melindungi masyarakat yang terbuka, layak, dan vital (Hobson, 2007).

Faktor lain yang menyebabkan masih rendahnya literasi sains siswa Indonesia berdasarkan penilaian PISA adalah siswa Indonesia belum terlatih dalam menyelesaikan soal-soal dengan karakteristik seperti soal-soal pada PISA. Padahal untuk meningkatkan literasi sains atau literasi ilmiah, guru juga memerlukan perangkat evaluasi yang berbasis literasi sains. Guru sering mengabaikan alat evaluasi berbasis literasi sains karena belum memahami bagaimana membuat perangkat evaluasi tersebut (Fraenkel, et al. 2012). Selain itu, faktor latar belakang siswa, minat, intensitas belajar, dan sikap siswa terhadap sains juga turut mempengaruhi rendahnya prestasi literasi sains siswa (Ekohariadi, 2009).

Materi sistem peredaran darah merupakan salah satu materi konsep yang terdapat pada jenjang Sekolah Menengah Pertama pada kelas VIII konsep IPA ini sesuai dengan aspek literasi sains. Materi yang abstrak tetapi konkrit dalam kehidupan sehari-hari, sedangkan proses pembelajaran di sekolah hanya menghafal saja, sehingga perlu menekankan literasi sains pada materi sirkulasi darah.

Sains memiliki fungsi yang sangat strategis karena dapat dipergunakan untuk mengembangkan potensi dan kemampuan-kemampuan siswa baik aspek kognitif (konten sains), aspek psikomotorik (proses sains) maupun aspek afektif (sikap sains) (Mundilarto, 2005). 


\section{Metode}

Penelitian ini merupakan penelitian deskriptif yang bertujuan untuk mengidentifikasi kemampuan literasi sains pada materi sirkulasi darah. Subjek penelitian 38 siswa SMP N 4 Belik Pemalang Jawa Tengah kelas VIIIA tahun ajaran 2018/2019. Instrumen yang digunakan adalah alat tes kemampuan literasi sains yang dikembangkan penulis dengan acuan indikator literasi sains.

Tabel 1. Kategori indikator

\begin{tabular}{|c|c|}
\hline No & Indikator Literasi \\
\hline 1. & Mengidentifikasi pendapat ilmiah yang valid \\
\hline 2. & $\begin{array}{l}\text { Memahami elemen- elemen desain penelitian dan } \\
\text { bagaimana dampaknya terhadap temuan/ kesimpulan }\end{array}$ \\
\hline 3. & $\begin{array}{l}\text { Mampu menyelesaikan soal berdasarkan fenomena } \\
\text { ilmiah dalam sistem peredaran darah }\end{array}$ \\
\hline 4. & $\begin{array}{l}\text { Memahami dan menginterpretasikan } \\
\text { statistik dasar }\end{array}$ \\
\hline 5. & $\begin{array}{l}\text { siswa mampu melakukan inferensi, prediksi, dan } \\
\text { penarikan kesimpulan berdasarkan data }\end{array}$ \\
\hline
\end{tabular}

\section{Hasil dan Pembahasan}

Berdasarkan hasil penelitian pada setiap indikator dapat dilihat pada Gambar 1.

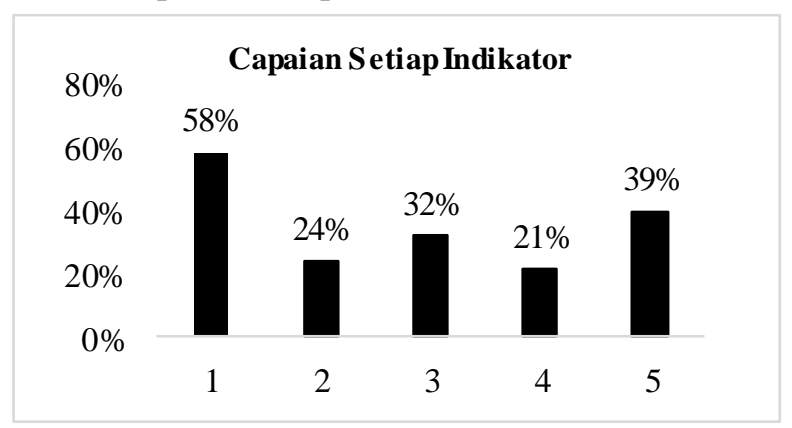

Gambar 1. Persentase Capaian Masing-Masing Indikator

Keterangan:

Aspek $1 \quad$ : Mengidentifikasi pendapat ilmiah yang valid

Aspek 2 : Memahami elemen-elemen desain penelitian dan bagaimana dampaknya terhadap temuan/ kesimpulan

Aspek 3 : Mampu menyelesaikan soal berdasarkan fenomena ilmiah dalam sistem peredaran darah

Aspek $4 \quad$ : Memahami dan menginterpretasikan statistik dasar

Aspek 5 : Siswa mampu melakukan inferensi, prediksi, dan penarikan kesimpulan berdasarkan data

Tampak dari aspek mengidentifikasi pendapat ilmiah yang valid dengan presentase (58\%) hal ini merupakan capaian indikator tertinggi jika dibandingkan dengan keempat aspek lainnya Guru menganggap penekanan literasi sains sebagai nyata meningkatkan minat siswa dan keterlibatan siswa (Millar, 2007). Memahami elemen-elemen desain penelitian terhadap temuan dengan capaian persentase (24\%) hal ini merupakan kedudukan dua terendah dari lima lainnya. Dimana siswa harus mampu berlatih lagi memahami data hasil penelitian dari berbagai sumber sebagai sarana sumber belajar, meningkatkan literasi dan pemahaman siswa.

Inidkator ketiga yaitu mampu menyelesaikan soal berdasarkan fenomena ilmiah $(32 \%)$ pada indikator ini siswa perlu banyak berlatih kembali dengan meningkatkan pemahaman konsep sains terintegrasi dengan fenomena dan kejadian di alam dan dalam kehiduan sehari-hari khususnya pada kasus sistem peredaran darah. Pendidikan sains menyoroti pemahaman siswa tentang konsep-konsep ilmu pengetahuan, penerapan pemahaman mereka untuk menjelaskan fenomena alam dalam memecahkan masalah sosial (Lambert, 2006). Banyak fenomena yang terjadi mulai dari proses peredaran darah, tekanan darah, penyumbatan darah dan proses menjaga agar memiliki jantung yang sehat.

Indikator keempat memahami dan menginterpretasikan statistik dasar (21\%) pada indikator ini banyak siswa yang perlu berlatih untuk menginterprestasikan sebuah sajian data. Hal tersebut juga mengindikasikan bahwa perlu adanya penguatan serta pembelajaran yang sifatnya dapat meningkatkan kemampuan literasi sains. Indikator kelima yaitu siswa mampu melakukan inferensi, prediksi, dan penarikan kesimpulan berdasarkan data (39\%).

Bentuk tertinggi dari suatu pemikiran siswa adalah penalaran (Kusairi, 2013). Literasi sains merupakan pengambilan keputusan-keputusan yang bertumpu pada penalaran seseorang berdasarkan ilmu atau konsep yang dimiliki. Secara sederhana penalaran dapat didefinisikan sebagai proses pengambilan kesimpulan berdasarkan ilmu yang diperoleh ketika di sekolah. Indrawati (2007) menyatakan bahwa kemampuan bernalar dalam memahami konsep yang dimaksud adalah membandingkan antar konsep (mengidentifikasi, konsep, mengklasifikasikan, memberi contoh), mengaplikasikan konsep, dan menyimpulkan suatu konsep.

Berdasarkan permasalahan dilapangan didapat beberapa faktor penyebab rendahnya literasi sains adalah: siswa belum pernah mengerjakan soal literasi sains sebelumnya yang berkaitan dengan hasil penelitian tema sistem peredaran darah. Kebiasaan siswa lebih suka menghapal materi pembelajaran dari pada memahaminya, sehingga siswa kurang memahami dan mengaplikasikan materi tersebut dalam kehidupan sehari-hari. Para pendidik seharusnya memiliki keterampilan literasi sains dan keterampilan berpikir kritis yang tinggi. Hal ini sangat penting agar mereka dapat mengembangkan keterampilan literasi sains siswanya (Jamaluddin, 2018). 
Guru-guru bidang sains seharusnya juga mampu memberikan perhatian penuh pada upaya untuk meningkatkan dan mengembangkan kemelekan sains (science literacy) (Jupri, 2018). Adapun model pembelajaran yg mempengaruhi dari model pembelajaran yang efektif dan tepat dapat membanru individu memiliki literasi sains dan teknologi serta memiliki kepedulian terhadap masalah masyarakat dan lingkungannya. Dengan model pembelajaran STM ini siswa diharapkan lebih aktif, termotivasi, dan hasil belajar siswa dapat meningkat (Hidayah, 2016).

Kurangnya minat membaca siswa dan tidak terbiasanya siswa menjawab soal dalam bentuk wacana, grafik, dan gambar. Temuan ini dapat membantu dalam proses merancang kurikulum, dan menekankan strategi instruksional tertentu untuk menumbuhkan literasi (Shwartz, et al, 2006). Penguasaan ilmu pengetahuan menunjukkan bahwa literasi sains masih rendah di bawah 50\% untuk semua kategori (Rusilowati, 2016).

\section{Kesimpulan}

Penelitian ini menunjukkan bahwa kemampuan literasi sains siswa pada kategori rendah. Hal ini tampak dari aspek mengidentifikasi pendapat ilmiah yang valid (58\%), memahami elemen-elemen desain penelitian terhadap temuan (24\%), mampu menyelesaikan soal berdasarkan fenomena ilmiah (32\%), memahami dan menginterpretasikan statistik dasar $(21 \%)$ dan siswa mampu melakukan inferensi, prediksi, dan penarikan kesimpulan berdasarkan data (39\%) kemampuan literasi sains siswa SMP rendah pada aspek memahami dan menginterpretasikan statistik dasar.

\section{Daftar Pustaka}

Harjono, A., Makhrus, M., Savalas, L. R. T., Rasmi, D. A. S. (2019). Pelatihan Pengembangan Perangkat Pembelajaran IPA Untuk Mendukung Kesiapan Guru Sebagai Role Model Keterampilan Abad 21. Jurnal Pendidikan dan Pengabdian Masyarakat. 2 (3).

Ekohariadi. (2009). Faktor-faktor yang Mempengaruhi Literasi Sains Siswa Indonesia Berusia 15 Tahun. Jurnal Pendidikan Dasar. 10(1).

Echols, J. M. \& Shadily, H. (1990). Kamus Indonesia Inggris: an Indonesian-English Dictionary. Jakarta: Penerbit PT Gramedia.

Fraenkel, J. R., Wallen, N. E., \& Hyun, H. H. (2012). How to Design and Evaluate Research in Education. Mc Graw-Hill Press. New York
Hidayah, L., Ayub, S., Hikmawati. (2016). Penerapan Model Pembelajaran Sains Teknologi Masyarakat (STM) untuk Meningkatkan Hasil Belajar Fisika Siswa Kelas VIII SMPN 3 Mataram. Jurnal Pendidikan Fisika dan Teknologi. (ISSN. 2407-6902). 2(3), pp. 111

Hobson, A. (2007). Teaching Relevant Science for Scientific Literacy. Routledge. 29 (11). pp. 1347-1362

Holbrook, J, \& Miia, R. (2010). The Nature of Science Education for Enhancing Scientific Literacy. Routledge. 29(11). pp. 1347-1362

Huryah, F., Sumarmin, R., \& Efendi, J. (2017). Analisis Capaian Literasi Sains Biologi Siswa SMA Kelas X di Kota Padang. Jurnal Eksakta Pendidikan, 1 (2). pp. 72-79.

Indrawati, S. (2007). Peningkatan kemampuan bernalar siswa didik melalui pembelajaran konstruktivistik. Jurnal pengembangan Manusia. 5(1).

Jamaluddin. (2018). Profil Literasi Sains Dan Keterampilan Berpikir Kritis Pendidik IPA SMP. Jurnal Penelitian Pendidikan IPA. 5 (1).

Jufri, A. W. (2018). Peningkatan Kompetensi Guru IPA Kota Mataram dalam Memfasilitasi Penguasaan Keterampilan Abad Ke 21 Siswa SMP. Jurnal Pengabdian Magister Pendidikan IPA, 1 (1). pp. 1-6.

Kusairi, S. (2012). Implementasi Blended Learning. Malang: Program Studi Pendidikan Fisika FMIPA UM

Lambert. (2006). High School Marine Science and Scientific Literacy: The promise of an integrated science course. International Journal of Science Education (IJSE). 28(6): pp. 633-654

Millar, R. (2007). Twenty First Century Science: Insights from the Design and Implementation School Science. International Journal of Science Education (IJSE). 28(13): pp. 14991521

Muhamad, F., Andayani, Y., Syarifa, W. A. I., Wildan. (2018). Hubungan Penulisan Jurnal Belajar Berbasis Literasi Sains Terhadap Hasil Belajar Siswa SMAN 2 Mataram. Jurnal. Chemistry Education Practice. 1 (2).

Taofiq, M., Dadi, S, Gito, H. (2018). Implementasi Model Pembelajaran Inkuiri Dan Problem Based Learning (PBL) Terhadap Keterampilan Generik Sains Biologi Ditinjau Dari Kemampuan Akademik Siswa. Jurnal Penelitian Pendidikan IPA (JPPIPA). 4(2): pp. 29-33.

Mundilarto. (2005). Optimalisasi Peran Hasil Penelitian Pendidikan dalam Peningkatan Kualitas Calon Guru Fisika. Pidato Pengukuhan Guru Besar. Yogyakarta: UNY. 
OECD. (2009). PISA 2009 Assesment Framework key Competencies in Reading, mathematics and Science [on-line]. Tersedia: http://www.oecd.

OECD. (2013). PISA 2012 Result: What Students Know and can Do-Student Performance in Mathemathics, Reading and Science (Volume I). PISA: OECD Publishing

Rusilowati, A., Lina, K., \& Sunyoto, E, N. (2016). Developing an Instrument of Scientific Literacy Asessment on the Cycle Theme. International Journal of Environmental \& Science Education (IJESE).11(12): pp. 5718-27.

Shwartz, Y., Ben-zvi, R., Hofstein, A. (2006). The Use of Scientific Literacy Taxonomy for Assessing the Development of Chemical Literacy among High-School Students. Springer.7 (4): pp. 203225 